\title{
Analysis of microbial populations in River-lake ecotone of Poyang Lake
}

\author{
Xiaolan HUANG ${ }^{1}$, Jian ZHANG ${ }^{1}$, Ting ZHANG ${ }^{1}$, Baoqing $\mathrm{Hu}^{2}$ \\ (1: School of Geography and Environment \& Key Laboratory of Poyang Lake Wetland and \\ Watershed Research, Ministry of Education, Jiangxi Normal University, Nanchang 330022, China. 2: \\ Ministry of Education Key Laboratory of Environment Change and Resources Use in Beibu Gulf \\ (Guangxi Teachers Education University), Nanning 530001, China) \\ E-mail: huangxiaolanlan@163.com
}

Keywords: Poyang Lake; River-lake ecotone; microbial populations

Abstract:Using the independent -cultivated molecular biology method, By Next-generation DNA sequencing techniques, Gene sequences of microbial groups for water samples collected from River-lake ecotone of Poyang Lake. water samples were collected form River-lake ecotone of Poyang Lake to determine gene sequences of microbial, using the independent-cultivated molecular biology method and Next-generation DNA sequencing techniques. The data showed that Poyang Lake had the largest number of unique microcal population, followed by the Yao River, the Ganjiang River, and the Rao River. The Species difference was smaller between samples in Ganjiang River and Rao River, while significant differences were found among Lake Poyang and the three other rivers. Poyang Lake was a huge microbial's genes pool, including a large number of the DNA sequence from ammonia oxidizing bacteria to animonia-oxidizing archare. It's expected to separate functional microorganisms which may play an important role in the earth nitrogen cycle.

\section{Introduction}

Poyang Lake is China's largest freshwater lake, located at $28^{\circ} 22$ ' $\mathrm{N}$ to $29^{\circ} 45^{\prime} \mathrm{N}, 115^{\circ} 47^{\prime} \mathrm{E}$ to $116^{\circ} 45^{\prime} \mathrm{E}$, on the southern bank of the middle and lower reaches of the Yangtze River in the northern Jiangxi Province. Poyang Lake swallows a large quantity of water coming from 5 tributaries, including Xiu River, Gan River, Fu River, Xin River and Rao River. Due to the unique hydrological regime and special geographical conditions, the water level of Poyang Lake is controlled by both its tributaries and the Yangtze River and has a great seasonal variation, This study takes the terrestrial - aquatic transverse zone of Poyang lake as a case, by Next-generation DNA sequencing techniques, Compared with the ordinary sequencing, the next -generation sequencing technology has the advantage of high flux, short test period, and is low-cost and repeatable $\mathrm{e}^{[1]}$. and has been widely used in all kinds of environments, such as soil ${ }^{[2]}$, ocean, hot spring, lakes and rivers ${ }^{[3]}$, the study sets the sampling points in Poyang Lake and Rao River ecotone (hxl3 and hxl1), Yao Lake and the Gan River ecotone (hu1 and he2), Based on the analysis of the characteristics of the microbial distribution, this work is helpful to enhance understanding between microbes population and environmental change.

\section{Methods}

Genomic DNA extractions from water samples

No. 1, 2, 3 and 4, bacterial genomic DNA were extracted from the water samples of Yao Lake, Gan River, Rao River and Poyang Lake, respectively. The molecular weight of genomic DNA 
extracted from these water samples was approximately $23 \mathrm{~kb}$, which was in agreement with the expected value.

Next - generation sequencing

The DNA was sequenced through the Illumina platform for Paired-end sequencing ${ }^{[4]}$, and the low quality reads were removed under the machine data. The statistical data is shown in Table 1 .

Table 1 Sample sequencing data statistics

\begin{tabular}{ccccccccc}
\hline $\begin{array}{c}\text { Sample } \\
\text { name }\end{array}$ & $\begin{array}{c}\text { Reads } \\
\text { length } \\
(\mathrm{bp})\end{array}$ & $\begin{array}{c}\text { Raw } \\
\text { data } \\
(\mathrm{Mbp})\end{array}$ & $\begin{array}{c}\text { Adapter } \\
(\%)\end{array}$ & $\begin{array}{c}\mathrm{N} \text { base } \\
(\%)\end{array}$ & $\begin{array}{c}\text { Ploy } \\
\text { base } \\
(\%)\end{array}$ & $\begin{array}{c}\text { Low } \\
\text { quality } \\
(\%)\end{array}$ & $\begin{array}{c}\text { Clean } \\
\text { data } \\
(\mathrm{Mbp})\end{array}$ & $\begin{array}{c}\text { Data } \\
\text { utilizati } \\
\text { on ratio } \\
(\%)\end{array}$ \\
\hline he2 & $250: 250$ & 251.23 & 0 & 0 & 0.017 & 6.438 & 225.22 & 89.65 \\
hu1 & $250: 250$ & 192.11 & 0 & 0 & 0.009 & 8.307 & 166.66 & 86.75 \\
hxl1 & $250: 250$ & 227.56 & 0 & 0 & 0.015 & 17.255 & 158.38 & 69.60 \\
hxl3 & $250: 250$ & 167.94 & 0 & 0 & 0.014 & 5.146 & 153.64 & 91.48 \\
\hline
\end{tabular}

In order to obtain high quality Tags, the splicing Tags sequence was processed. At the 0.97 level of clustering similarity for species classification of OTU (Operational Taxonomic Units), a total of 8657 OTU were obtained for the samples. Statistical results of sample OTU were in table 2.

Table 2 Sample OTU statistics

\begin{tabular}{ccccc}
\hline Sample name & Tag number & OTU number & $\begin{array}{c}\text { OTU number } \\
\text { (removing } \\
\text { singletons) }\end{array}$ & $\begin{array}{c}\text { Non singletons } \\
\text { OTU ratio (\%) }\end{array}$ \\
\hline he2 & 353,270 & 1,851 & 1,493 & 80.66 \\
hu1 & 283,182 & 2,813 & 1,681 & 59.76 \\
hxl1 & 265,326 & 1,491 & 1,169 & 78.40 \\
hxl3 & 241,012 & 4,390 & 3,047 & 69.41 \\
\hline
\end{tabular}

\section{Results and Discussion}

The most abundant microbial populations was Proteobacteria, Followed by Bacteroidetes, then Actinobacteria, Acidobacteria, Verrucomicrobia, Firmicutes, Planctomycetes Etc. A number of 2974 Crenarchaeota was detected In Poyang Lake, and a little Crenarchaeota in Rao River(table 3). 
Table 3 abundance of each sampling point of main microorganisms (Tags number)

\begin{tabular}{lcccc}
\hline Taxon & he2 & hu1 & hxll & hxl3 \\
\hline Crenarchaeota & 0 & 0 & 3 & 2974 \\
Euryarchaeota & 443 & 2 & 162 & 1 \\
Other Archaea & 103 & 2 & 70 & 7272 \\
Acidobacteria & 1265 & 35 & 400 & 57158 \\
Actinobacteria & 31728 & 50758 & 62200 & 13525 \\
Armatimonadetes & 529 & 4 & 3437 & 1018 \\
Bacteroidetes & 63464 & 69527 & 42588 & 28077 \\
Chlamydiae & 459 & 31 & 219 & 30 \\
Chloroflexi & 324 & 0 & 335 & 687 \\
Fusobacteria & 1596 & 50 & 153 & 0 \\
Gemmatimonadetes & 437 & 532 & 97 & 266 \\
Nitrospira & 26 & 0 & 20 & 462 \\
Planctomycetes & 3980 & 5178 & 1519 & 3949 \\
Proteobacteria & 189505 & 132484 & 107727 & 80613 \\
Verrucomicrobia & 22941 & 14143 & 20069 & 8332 \\
Firmicutes & 8832 & 1049 & 1974 & 2551 \\
\hline
\end{tabular}

America scholars ${ }^{[5]}$ successfully isolated a strain of Crenarchaeota Nitrosopumilus maritimus from the sea for the first time in 2005, which contained ammonia oxidation that needs ammonia monooxygenase gene amoA, It can oxidize ammonia nitrogen to obtain the energy assimilation of inorganic carbon growth. Ammonia-oxidizing bacteria nitrosomonas were relatively rich in Poyang Lake, but it was not detected in the Yao Lake Water. Nitrospira has an effect on nitrification and nitrite oxidation ${ }^{[6]}$, and mainly distributed in the environment that is affected by human activities. The Chlamydiae was found in Ganjiang River water flowing through the Nanchang city, which is a kind of special bacteria that can only survive in the cytoplasm, and mainly includes two kinds of bacteria, Chlamydia trachomatis and Chlamydia psittaci. Chlamydia trachomatis usually only infects humans, while Chlamydia psittaci can infect many kinds of animal and birds, and lead to respiratory diseases, abortion, and arthritis. Archaea in Yao Lake were rare, and Fusobacteria was most abundant in the Ganjiang River water. Studies ${ }^{[7]}$ have found out that Fusobacterium is unusually active in colon cancer cells, and seems to coexist with tumor malignant degree. The planctomycetes also contained some species such as Candidatus Brocadia, Candidatus Kuenenia and Candidatus Scalindua, They are called anaerobic ammonia oxidation bacteria, as they can use nitrite under hypoxia (NO2-) oxidation of ammonium ion (NH4+) generated nitrogen to obtain energy.It has the vital significance to the global nitrogen cycle, and also important in wastewater treatment. On the whole, microbial components in different geographic space were both related and changed with different environments .

\section{Acknowledgements}

This work was Supported by the National Natural Science Foundation of China (No. 41561002), the Collaborative Innovation Center for Major Ecological Security Issues of Jiangxi Province and Monitoring Implementation (No. JXS-EW-00), the Opening Foundation of Key Laboratory of Environment Change and Resources Use in Beibu Gulf (Guangxi Teachers EducationUniversity), Ministry of Education, China (No.2014BGERLKF02). 


\section{References}

[1] Mardis, E.R. 2008, The impact of next-generation sequencing technology on genetics. Trends Genet 24: 133-141.

[2] Woo HL, Hazen TC, Simmons BA, DeAngelis KM.. 2014, Enzyme activities of aerobic lignocellulolytic bacteria isolated from wet tropical forest soils. Syst Appl Microbial. 37(1):60-67.

[31] Egas C, Barroso C, Froufe HJ, Pacheco J, Albuquerque L, da Costa MS.. 2014, Complete genome sequence of the Radiation-Resistant bacterium Rubrobacter radiotolerans RSPS-4. Stand Genomic Sci. 9(3):1062-1075.

[4]Mao Y, Xia Y, Zhang T. 2013, Characterization of Thauera-dominated hydrogen-oxidizing autotrophic denitrifying microbial communities by using high-throughput sequencing. Bioresour Technol. 128:703-10.

[5].Könneke M, Bernhard AE, de la Torre JR, Walker CB, Waterbury JB, Stahl DA. 2005, Isolation of an autotrophic ammonia-oxidizing marine archaeon. Nature, 437(7058): 543-546.

[6]Wang C, Liu J, Wang Z, Pei Y. 2014, Nitrification in lake sediment with addition of drinking water treatment residuals. Water Res. 56(1):234-45.

[7]Kostic AD, Chun E, Robertson L, Glickman JN, Gallini CA, Michaud M, Clancy TE, Chung DC, Lochhead P, Hold GL, El-Omar EM, Brenner D, Fuchs CS, Meyerson M, Garrett WS.. 2013, Fusobacterium nucleatum potentiates intestinal tumorigenesis and modulates the tumor-immune microenvironment. Cell Host Microbe. 14(2):207-15. 